\title{
Research responsibilities
}

The debate on the UK Government's recent Research Assessment Exercise (RAE), which has grown steadily over our past two issues (5/4 and 6/1), reaches a climax in this one. Perhaps the time has come to ask whether arq is becoming parochial in its focus on a matter that seems of concern only to the UK. However, we offer no apologies for using the RAE debate to highlight the research crisis in architecture - a crisis that is by no means confined to the UK.

There are many issues under discussion. There is the simple matter of the 'accuracy' of the system in recognising high quality work: our correspondents (pp. 101-103) seem divided on this. Then there is the question of 'fairness' in the size of the financial reward: the sums available for distribution meant that many who performed well were awarded less than in the last round. And there is the ever recurring question of design as 'research': Bryan Lawson's contribution (pp. 109-114) surely provides the last word on this

Three correspondents widen the debate beyond the RAE. Colin Stansfield Smith (p. 104) writes of a procurement system in which architecture has become marginalised. John Worthington (p. 104) makes a plea for both the profession and the schools to look outwards. And, almost incredibly, the letter from the outgoing RIBA Vice President for Education, Alan Jones (p. 105), seems to suggest that arq 's prodding may have provoked coordinated action within the Institute.

The latest news is that the two incoming Vice Presidents for Education and Practice, Jack Pringle and Richard Saxon, are practitioners who are determined to bridge the gap between the profession and academia. Each is committed to promoting, supporting and disseminating research. Both see it not as a problem to be ignored but as an opportunity to be grasped. We wish them every success.

There is much to be done. Real needs must be identified and matched to available means in academia and practice; valuable unpublished material uncovered; appropriate methods of dissemination developed; and a realistic implementation strategy evolved. If the RIBA could, in partnership with practice and academia, develop such a programme, it would, in the process, acquire the ability to support the architecture schools in the pursuit of their own (and the profession's) interests. It would also enable the profession to speak with the kind of authority that the RICS Foundation has given the surveyors.

It is this wider agenda with which arq is concerned. If leading-edge practitioners and academics have a duty to enhance the profession's knowledge base then professional institutes have a responsibility as its guardians and sponsors. All must work together in a world in which architecture is increasingly under threat. 